\title{
Efficacy of Tiotropium as Add-on Therapy for Adults with Uncontrolled Asthma
}

\author{
Ralph Elvi M. Villalobos, Charles Vincent O. Uy, Marc Gregory Y. Yu and Manuel C. Jorge \\ Department of Medicine, College of Medicine and Philippine General Hospital, University of the Philippines Manila
}

\begin{abstract}
Objective. The study aimed to evaluate efficacy of tiotropium as add-on therapy on top of standard regimens for uncontrolled asthma, specifically in terms of FEV1, morning and evening PEF, reduction in exacerbations, rescue medication use, and quality of life improvement.

Methods. A search was done for eligible trials after which validity screen and data extraction was performed. Results were presented as mean differences, standard errors, and 95\% confidence intervals, and graphically as forest plots. Estimates were pooled using the random effects model, with $\mathrm{I}^{2}$ and $\mathrm{Chi}^{2}$ tests used to assess heterogeneity. Adverse events were reported as dichotomous variables.

Results. Four studies were included totaling 1617 participants. The tiotropium group had statistically significant improvement in FEV1 $(95 \% \mathrm{Cl}, 0.14$ [0.09, 0.19], $\mathrm{p}<0.00001)$, morning $(95 \% \mathrm{Cl}$, 20.03 [11.71, 28.35], $\mathrm{p}<0.00001)$, and evening PEF (95\% Cl, 23.13 $[15.18,31.09], p<0.00001)$ with trend towards benefit in reduction of rescue medications $(95 \% \mathrm{Cl}, 0.12[-0.17,0.4], \mathrm{p}=$ $0.42)$ and quality of life improvement $(95 \% \mathrm{Cl}, 0.1[-0.05,0.25]$, $\mathrm{p}=0.20$.) Homogeneity $\left(\mathrm{I}^{2}=0 \%, \mathrm{Chi}^{2}=0.47-3.22\right)$ was found across studies.
\end{abstract}

Conclusion. Tiotropium is associated with significant improvement in pulmonary function among patients with uncontrolled asthma, with possible benefit in reduction of rescue medications and quality of life improvement.

Key Words: asthma, tiotropium, bronchodilator agents, clinical respiratory medicine, meta-analysis

Awarded Best Meta-analysis Poster at the 43rd Philippine College of Physicians (PCP) Annual Convention, May 5-8, 2013 ,SMX Convention Center, Manila. Presented at the European Respiratory Society (ERS) Annual Congress, September 7-11, 2013, Barcelona, Spain, and at the 18th Asia Pacific Respiratory Society (APSR) Annual Congress, November 11-14, 2013, Yokohama, Japan.

Corresponding author: Ralph Elvi M. Villalobos, MD

Section of Pulmonary Medicine

Department of Medicine

Philippine General Hospital

University of the Philippines Manila

Telephone: +632 5672399

Email: ralphvillalobos@yahoo.com

\section{Introduction}

A significant proportion of asthma patients have severe persistent disease. ${ }^{1,2,3}$ These patients are characterized by three or more features of the following: more than two daytime symptoms or need for rescue medication per week; activity limitation; nocturnal awakening; and peak expiratory flow (PEF) or one-second pre-bronchodilator forced expiratory volume (FEV1) $<80 \%$ predicted or personal best. ${ }^{4}$ Treatment usually consists of controller drugs in the form of inhaled steroids (ICS) with or without long-acting beta-2 agonists (LABA), oftentimes with the addition of various other bronchodilators including anti-leukotrienes and theophyllines. However, progressive airflow obstruction is commonly observed in these patients ${ }^{5,6}$ and may be due to airway remodeling secondary to uncontrolled chronic airway inflammation. ${ }^{7}$ The fibrotic changes seen in remodeled airways can be unresponsive to standard therapy, and as such ever-increasing doses of medications can be ineffective. Furthermore, alternative treatment options may have substantial limitations including marginal efficacy, cumbersome routes of administration, and high cost. ${ }^{4,8}$

A potential approach is the addition of a second bronchodilator with an alternative mechanism of action the long-acting anticholinergic tiotropium - which has been shown to be effective in patients with chronic obstructive pulmonary disease (COPD), in whom it is widely used. ${ }^{9,10}$ Tiotropium has a long duration of action of more than 24 hours ${ }^{11}$ which is attributed to its slow dissociation from muscarinic receptors. ${ }^{12}$ Until recently, reports on its efficacy as maintenance treatment in asthmatic patients were limited to case reports, uncontrolled open label studies, and similar other assessments. ${ }^{13,14}$ Whether tiotropium is useful for the management of asthma, is, up to now, not firmly established, and it is not included in asthma treatment guidelines. ${ }^{15}$

In a large randomized controlled trial (RCT) involving patients with moderate-severe COPD and a history of asthma, the use of tiotropium showed a significant improvement in lung function and a reduction in use of rescue medications. ${ }^{16}$ Moreover, a number of other RCTs have recently investigated the role of tiotropium in asthmatic patients who were already on standard treatment regimens. These studies compared tiotropium with either placebo, addition of the LABA salmeterol, or doubling the 
dose of ICS in patients taking ICS alone.,17-20 Tiotropium was revealed to be non-inferior to alternative treatment, in addition to effecting superior improvements in FEV1, morning and evening PEF, symptoms, and several other outcomes. $^{20}$ This review aims to consolidate current available information and evaluate the efficacy of tiotropium as add-on therapy on top of the currently approved medications for treatment of uncontrolled asthma, and determine whether any observed changes would translate into clinically relevant outcomes.

\section{Objectives}

The study aimed to evaluate efficacy of tiotropium as add-on therapy on top of standard regimens for uncontrolled asthma, specifically in terms of FEV1, morning and evening $\mathrm{PEF}$, reduction in exacerbations and rescue medication use, and improvement of quality of life.

\section{Methods}

The study was performed in accordance with the Quality of Reporting of Meta-Analyses (QUORUM) guidelines and was approved by the local technical and ethics review board prior to commencement.

\section{Data Sources}

Electronic databases such as MEDLINE, ClinicalTrials.gov, Google Scholar, and the Cochrane Central Register of Controlled Trials were systematically searched for the terms "tiotropium," "long acting anticholinergic," or "Spiriva," and "severe asthma," "persistent asthma," or "uncontrolled asthma." The search was restricted to randomized controlled trials and existing meta-analyses. No linguistic or temporal restrictions were imposed. Searches were current as of 08 September 2012.

The references of the chosen articles were also browsed for possible inclusion in the study. The only existing manufacturer of tiotropium, Boehringer Ingelheim (where the drug is marketed under the brand name Spiriva), was also contacted via email for possible inclusion of unpublished studies.

\section{Study Selection}

\section{Types of Studies}

Randomized controlled trials or existing metaanalyses involving the use of tiotropium as add-on therapy on top of standard medications for uncontrolled asthma, as compared to placebo or alternative add-on regimens, were included in this review. Based on pharmacologic studies showing the attainment of a clinically observable steady state effect in patients administered with tiotropium, only trials that followed up patients for three weeks or more after randomization were included.

\section{Types of Participants}

Studies involving adults $>18$ years of age with uncontrolled asthma, as defined in the Global Initiative for Asthma (GINA) 2011, who were on optimal doses of controller medications were included in this review. Patients who are current or previous smokers or those with diagnosed COPD or other concomitant respiratory illnesses were excluded. There were no restrictions on ethnicity or gender.

\section{Types of Interventions}

Tiotropium was the exposure of interest and was administered as an add-on drug for patients with uncontrolled asthma currently on optimal doses of controller medications (ICS with or without LABA), as compared to placebo, LABA, or doubling ICS doses.

\section{Types of Outcome Measures}

The primary outcome was an improvement in FEV1. Secondary outcomes included improvement in morning and evening PEF; frequency of rescue medication use; changes in symptom scores and quality of life as measured through the mini-Asthma Quality of Life Questionnaire (mini-AQLQ); reduction in the number of exacerbations; and the nature and frequency of adverse events.

\section{Data Extraction and Management}

Three authors independently screened eligibility of trials for potential inclusion in the review, using a data eligibility form based on the above criteria for study selection. Studies agreed upon for exclusion by all reviewers were excluded at this stage, with the reason for exclusion documented in all cases. Eligible studies then underwent a thorough assessment of study quality using a methodological quality assessment form based on the Cochrane Collaboration's tool for assessing risk of bias. The validity criteria included randomization, allocation concealment, baseline characteristics, blinding, and adequacy of follow-up. Any disagreements were resolved by consensus, referring back to the original article.

Studies that passed all screenings underwent data extraction, performed independently by all authors using a customized data extraction form. The following data were extracted from each of trial: author, year of publication, duration of study including run-in period, type of comparator, total sampling population with baseline characteristics, and study outcomes.

Changes in FEV1, morning and evening PEF, frequency of rescue medication use, symptom scores and quality of life as measured via the mini-AQLQ, and the number of exacerbations and adverse events were used as measures of treatment effect. 


\section{Statistical Analysis}

The study was analyzed using Review Manager (version 5). Results were presented as mean differences and standard errors with 95\% confidence intervals, and graphically presented as forest plots. Estimates were calculated using the inverse variance method for continuous variables and pooled using the random effects model. Isquare and Chi square tests, as well as inspection of forest plots, were utilized for assessment of heterogeneity, defined as $\mathrm{I}^{2}>50$ and $\mathrm{p}<0.1$ for the $\mathrm{I}^{2}$ and $\mathrm{Chi}^{2}$ tests, respectively.

Unit of analysis issues were resolved by looking for uniformity among the analyses of individual studies. In cases of multiple observations for the same outcome, it was agreed upon that the last measure will be included in the study. Missing data was dealt with by contacting trial authors, using open-ended questions, and by performing intention to treat analyses. Funnel plots were used in reporting publication biases. Adverse events were reported as dichotomous variables.

\section{Results}

\section{Trial Flow}

Nineteen articles discussing the potential role of tiotropium in asthma were initially retrieved. However, only nine were deemed eligible for inclusion; the other ten articles were excluded mainly because they were only case reports, case series, or mere descriptive studies. Of the nine initially screened-in articles, five were further excluded because they were either not randomized, were only open clinical trials without control groups, or did not meet the criteria for outcome variables. Four studies ultimately satisfied the selection criteria and were included in the analysis. Figure 1 shows the general flowchart for study selection, while the list of the four included studies, together with their corresponding characteristics, is outlined in Table 1. Table 2, on the other hand, summarizes the methodological quality assessment results for each of the included studies.

Table 1. Characteristics of the studies included in the review.

\begin{tabular}{|c|c|c|c|c|c|}
\hline $\begin{array}{l}\text { Author/ } \\
\text { Year }\end{array}$ & Title & Design & $\begin{array}{c}\text { Duration/N/ } \\
\text { Run-in }\end{array}$ & Outcomes & Comparison \\
\hline $\begin{array}{c}\text { Peters et al } \\
2010\end{array}$ & $\begin{array}{l}\text { Tiotropium bromide step-up } \\
\text { therapy for adults with } \\
\text { uncontrolled asthma }\end{array}$ & $\begin{array}{c}\text { RCT } \\
\text { Crossover design }\end{array}$ & $\begin{array}{l}\text { Duration: } 52 \mathrm{wk} \\
\qquad \mathrm{N}=210 \\
\text { Run-in }=4 \mathrm{wk}\end{array}$ & $\begin{array}{c}\text { PEF, FEV1, Rescue } \\
\text { medication use, AQLQ } \\
\text { scores }\end{array}$ & $\begin{array}{c}\text { Placebo } \\
\text { Doubling ICS } \\
\text { dose }\end{array}$ \\
\hline $\begin{array}{l}\text { Kerstjens et al } \\
2011\end{array}$ & $\begin{array}{l}\text { Tiotropium improves lung } \\
\text { function in patients with severe } \\
\text { uncontrolled asthma: a } \\
\text { randomized controlled trial }\end{array}$ & $\begin{array}{c}\mathrm{RCT} \\
\text { Separate experimental and } \\
\text { control }\end{array}$ & $\begin{array}{l}\text { Duration: } 24 \mathrm{wk} \\
\qquad \mathrm{N}=107 \\
\text { Run-in=2 wk }\end{array}$ & PEF, FEV1 & Placebo \\
\hline $\begin{array}{c}\text { Bateman et al } \\
2011\end{array}$ & $\begin{array}{l}\text { Tiotropium is noninferior to } \\
\text { salmeterol in maintaining } \\
\text { improved lung function in B16- } \\
\text { Arg/Arg patients with asthma }\end{array}$ & $\begin{array}{c}\text { RCT } \\
\text { Crossover design }\end{array}$ & $\begin{array}{l}\text { Duration: } 16 \mathrm{wk} \\
\qquad \mathrm{N}=388 \\
\text { Run-in }=4 \mathrm{wk}\end{array}$ & $\begin{array}{c}\text { PEF, FEV1, Rescue } \\
\text { medication use, asthma } \\
\text { symptoms, AQLQ scores }\end{array}$ & $\begin{array}{c}\text { Placebo } \\
\text { Salmeterol }\end{array}$ \\
\hline $\begin{array}{l}\text { Kerstjens et al } \\
2012\end{array}$ & $\begin{array}{l}\text { Tiotropium in asthma poorly } \\
\text { controlled with standard } \\
\text { combination therapy }\end{array}$ & $\begin{array}{c}\text { RCT } \\
\text { Separate experimental and } \\
\text { control } \\
(2 \text { arms })\end{array}$ & $\begin{array}{l}\text { Duration: } 48 \mathrm{wk} \\
\qquad \mathrm{N}=912 \\
\text { Run-in }=4 \mathrm{wk}\end{array}$ & $\begin{array}{c}\text { PEF, FEV1, Rescue } \\
\text { medication use, asthma } \\
\text { symptoms, exacerbation } \\
\text { AQLQ scores }\end{array}$ & Placebo \\
\hline
\end{tabular}

Table 2. Methodological quality assessments for studies included in the review.

\begin{tabular}{|c|c|c|c|c|c|}
\hline Study & Randomization & Allocation Concealment & Baseline Characteristics & Blinding & Follow up Rates \\
\hline $\begin{array}{c}\text { Peters et al } \\
2010\end{array}$ & Adequate & $\begin{array}{c}\text { Unclear } \\
\text { (not mentioned) }\end{array}$ & No significant difference & Double blind & $\begin{array}{c}\text { Adequate, } \\
\text { intention to treat analysis }\end{array}$ \\
\hline $\begin{array}{l}\text { Kerstjens et al } \\
2011\end{array}$ & $\begin{array}{c}\text { Adequate } \\
\text { (pseudorandom number } \\
\text { generator) }\end{array}$ & $\begin{array}{c}\text { Unclear } \\
\text { (not mentioned) }\end{array}$ & No significant difference & Double blind & $\begin{array}{c}\text { Adequate, } \\
\text { per protocol analysis }\end{array}$ \\
\hline $\begin{array}{l}\text { Bateman et al } \\
2011\end{array}$ & Adequate & $\begin{array}{c}\text { Unclear } \\
\text { (not mentioned) }\end{array}$ & No significant difference & Double blind & Adequate \\
\hline $\begin{array}{l}\text { Kerstjens et al } \\
2012\end{array}$ & $\begin{array}{c}\text { Adequate } \\
\text { (pseudorandom number } \\
\text { generator) }\end{array}$ & $\begin{array}{c}\text { Unclear } \\
\text { (not mentioned) }\end{array}$ & No significant difference & Double blind & $\begin{array}{l}\text { Adequate, intention to } \\
\text { treat analysis }\end{array}$ \\
\hline
\end{tabular}




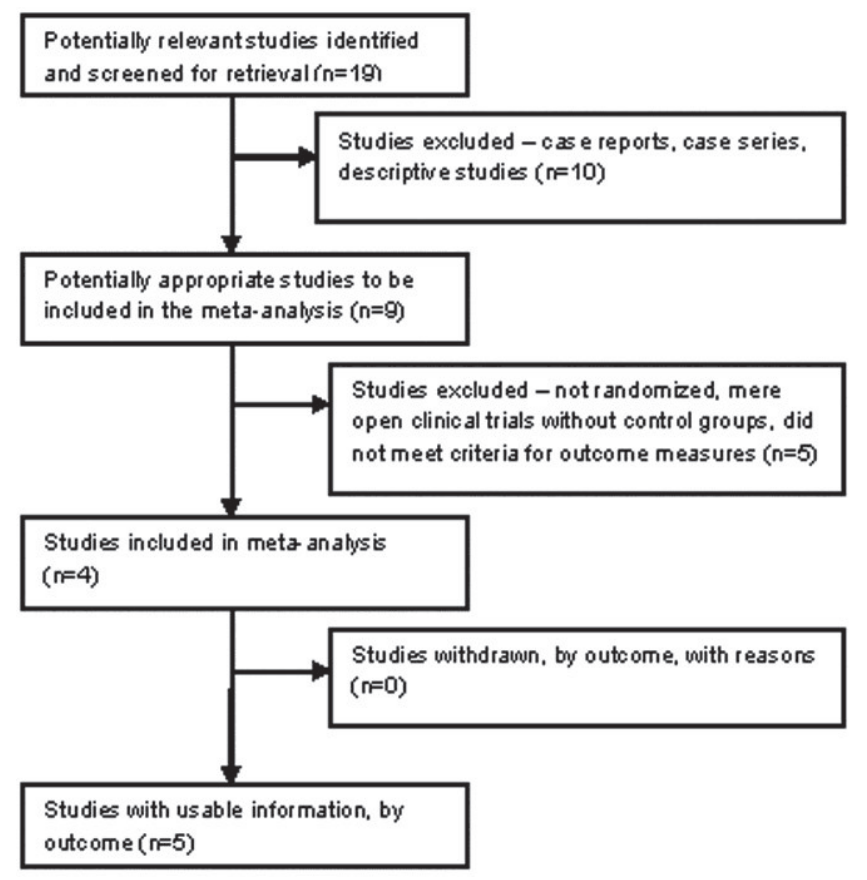

Figure 1. Flowchart of the process of retrieval and selection of studies for the review.

\section{Study Characteristics}

Of the four selected studies, two ${ }^{17,20}$ had a crossover design while the other $\mathrm{two}^{3,19}$ had separate experimental and control groups. One study ${ }^{3}$ had two different arms (one performed in 2009 and the other in 2011) employing the same control and experimental groups with a different set of patients enrolled; the investigators only merged the results into a single publication. Duration of the studies ranged from 16-52 weeks. All of the studies were published within the past three years.

All studies compared tiotropium with placebo. One study further compared tiotropium with doubling the dose of the existing ICS, while another also compared tiotropium with the LABA salmeterol. With regards to methodological quality, all studies were double-blind RCTs, and all had adequate rates of follow-up. Two studies ${ }^{19,20}$ mentioned the use of intention-to-treat analysis while one study ${ }^{3}$ stated the use of per protocol analysis. Baseline characteristics of the compared groups in all studies yielded no significant differences. Allocation concealment, however, was not explicitly mentioned in any of the studies.

A total of 1617 participants were enrolled in the four studies. The ages of the participants ranged from 18-75 years, with the majority being Caucasians. All participants had uncontrolled asthma with optimal doses of controller medications.

Since placebo was the only control group consistently present in all of the included studies, the study authors decided to use the placebo arm as the control group in all outcome measures.

\section{Data Synthesis: Pulmonary Function}

\section{Mean Difference in FEV1 Change from Baseline}

All studies reported FEV1 change from baseline as the primary outcome of interest, with measurements done at baseline and on follow up. A statistically significant difference (95\% CI, 0.14 [0.09, 0.19], p<0.00001) in FEV1 values was found among patients treated with tiotropium compared to controls (Figure 2). Based on the forest plot, an overall benefit favoring the tiotropium group was observed, with no significant heterogeneity noted across all studies $\left(\mathrm{I}^{2}=0 \%, \mathrm{Chi}^{2}=1.57\right)$.

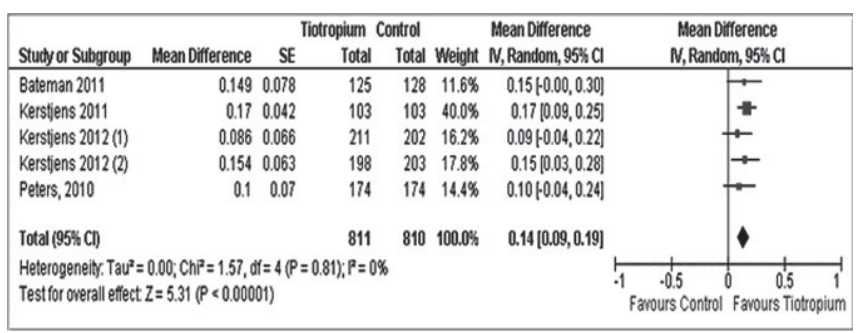

Figure 2. Mean difference in FEV1 (L) between the tiotropium and control groups.

\section{Mean Difference in Morning and Evening PEF Change from Baseline}

A statistically significant difference was also noted in both morning (95\% CI, 20.03 [11.71, 28.35], p<0.00001) and evening (95\% CI, 23.13 [15.18, 31.09], p<0.00001) PEF values among patients treated with tiotropium, as shown in Figures 3 and 4, respectively. Similar to the FEV1 forest plot, the graph of both morning and evening PEFs in all studies showed overall benefit favoring the tiotropium group. Likewise, no significant heterogeneity was found across all studies for either outcome $\left(\mathrm{I}^{2}=0[\mathrm{both}], \mathrm{Chi}^{2}=0.92\right.$ [morning $\mathrm{PEF}$ ], $\mathrm{Chi}^{2}=3.22$ [evening PEF]).

\begin{tabular}{|c|c|c|c|c|c|c|c|}
\hline \multirow[b]{2}{*}{ Study or Subgroup } & \multirow[b]{2}{*}{ Mean Difference } & \multicolumn{3}{|c|}{ Tiotropium Control } & \multirow{2}{*}{$\begin{array}{l}\text { Mean Difference } \\
\text { N, Random, } 95 \% \mathrm{Cl}\end{array}$} & \multirow{2}{*}{\multicolumn{2}{|c|}{$\begin{array}{l}\text { Mean Difference } \\
\text { N, Random, } 95 \% \mathrm{Cl}\end{array}$}} \\
\hline & & SE & Total & Total Weight & & & \\
\hline Kerstiens 2011 & 15.3 & 6.7 & 103 & $10340.1 \%$ & $15.30[2.17,28.43]$ & & t- \\
\hline Kerstiens 2012 (1) & 21.5 & 8.9 & 211 & $202 \quad 22.7 \%$ & 21.50 & & $\rightarrow$ \\
\hline Kerstiens 2012 (2) & 23.3 & 8.8 & 198 & $203 \quad 23.3 \%$ & 23.30 & & $\rightarrow$ \\
\hline Peters, 2010 & 25.8 & 11.4 & 174 & $174 \quad 13.9 \%$ & $25.80[3.46,48.14]$ & & \\
\hline Total (95\% CD) & & & 686 & $682100.0 \%$ & $20.03[11.71,28.35]$ & & 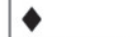 \\
\hline \multicolumn{5}{|c|}{ 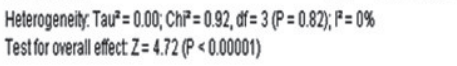 } & & $\begin{array}{l}.500 \quad .50 \\
\text { Farours Con }\end{array}$ & $\begin{array}{|lll|}0 & 50 & 100 \\
\text { Favours Tiotropium }\end{array}$ \\
\hline
\end{tabular}

Figure 3. Mean difference in morning PEF (L/min) between the tiotropium and control groups. 


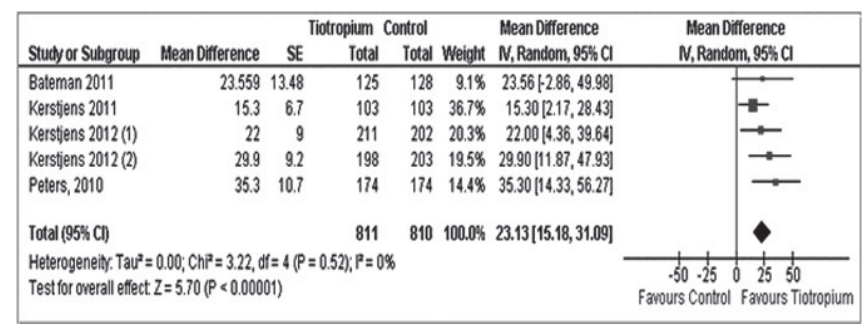

Figure 4. Mean difference in evening PEF (L/min) between the tiotropium and control groups.

\section{Data Synthesis: Clinical Outcomes}

\section{Reduction in Rescue Medication Use}

Three studies (with one study having two arms) 3,17,19 included reduction in rescue medication use as outcome measures. Pooling of results showed no statistically significant difference (95\% CI, 0.12 [-0.17, 0.4], p= 0.42) between the tiotropium and control groups, although the forest plot (Figure 5) revealed an overall trend towards benefit favoring the tiotropium group. Even so, a wide variation among the results of individual studies can be noticeably observed, owing to the discrete nature of data. No significant heterogeneity was found $\left(\mathrm{I}^{2}=0 \%, \mathrm{Chi}^{2}=0.54\right)$.

\begin{tabular}{|c|c|c|c|c|c|c|}
\hline \multirow[b]{2}{*}{ Study or Subgroup } & \multirow[b]{2}{*}{ Mean Difference } & \multicolumn{3}{|c|}{ Tiotropium Control } & \multirow{2}{*}{$\begin{array}{l}\text { Mean Difference } \\
\text { N, Random, } 95 \% \mathrm{Cl}\end{array}$} & \multirow{2}{*}{$\begin{array}{l}\text { Mean Difference } \\
\text { N, Random, } 95 \mathrm{Gl} \text { Cl }\end{array}$} \\
\hline & & SE & Total & Total Weight & & \\
\hline Bateman 2011 & 0.368 & 0.496 & 125 & $128 \quad 8.4 \%$ & $0.37[-0.60,1.34]$ & \\
\hline Kerstens 2012 (1) & 0.09 & 0.33 & 211 & $20219.0 \%$ & $0.09[-0.56,0.74]$ & \\
\hline Kerstiens 2012 (2) & 0.26 & 0.37 & 198 & $203 \quad 15.1 \%$ & $0.26[-0.47,0.99\}$ & \\
\hline Peters, 2010 & 0.05 & 0.19 & 174 & $17457.4 \%$ & $0.05[-0.32,0.42]$ & \\
\hline Total (95\% Cl) & & & 708 & $707100.0 \%$ & $0.12[-0.17,0.40]$ & \\
\hline \multicolumn{6}{|c|}{$\begin{array}{l}\text { Heterogeneily. Ta } u^{2}=0.00 ; C^{2} P^{2}=0.54, d f=3(P=0.91) ; P=0 \% \\
\text { Test for overall effect } z=0.81(P=0.42)\end{array}$} & 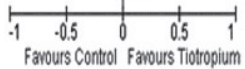 \\
\hline
\end{tabular}

Figure 5. Mean difference in frequency of rescue medication use (puffs per 24 hours) between the tiotropium and control groups.

\section{Improvement in Quality of Life (measured via mini-AQLQ score)}

The mini-AQLQ is a validated, asthma-specific instrument containing 15 questions across four domains (symptoms, activities, emotions and environment.) ${ }^{18}$ The review noted no statistically significant difference between the tiotropium and control groups (95\% CI, 0.1 [-0.05, 0.25], $\mathrm{p}=0.20$ ) with regards to mini-AQLQ scores, while the forest plot showed an overall trend towards benefit (Figure 6). No significant heterogeneity was also found across all studies $\left(\mathrm{I}^{2}=0 \%, \mathrm{Chi}^{2}=0.47\right)$.

\section{Adverse Events}

Data on adverse events is shown in Table 3. A statistically significant difference in the occurrence of asthma exacerbations ( $p<0.0001$ ) was noted between the tiotropium and control groups, in favor of the tiotropium group. Other adverse events observed included nasopharyngitis, headache, bronchitis, and upper respiratory tract infection.

\begin{tabular}{|c|c|c|c|c|c|c|}
\hline \multirow[b]{2}{*}{ Study or Subgroup } & \multirow[b]{2}{*}{ Mean Difference } & \multicolumn{3}{|c|}{ Tiotropium Control } & \multirow{2}{*}{$\begin{array}{l}\text { Mean Difference } \\
\text { I N, Random, } 95 \% \mathrm{Cl}\end{array}$} & \multirow{2}{*}{$\begin{array}{c}\text { Mean Difierence } \\
\mathrm{N}, \text { Random, } 95 \% \mathrm{Cl}\end{array}$} \\
\hline & & SE & Total & Total Weight & & \\
\hline Bateman 2011 & 0.091 & 0.174 & 125 & $128 \quad 20.3 \%$ & $0.09[0.25,0.43]$ & 1 \\
\hline Kerstiens 2012 (1) & 0.04 & 0.14 & 211 & $20231.3 \%$ & $0.04[-0.23,0.31]$ & + \\
\hline Kerstiens 2012 (2) & 0.18 & 0.15 & 198 & $20327.3 \%$ & $0.18[-0.11,0.47]$ & $t$ \\
\hline Peters, 2010 & 0.1 & 0.17 & 174 & $174 \quad 21.2 \%$ & $0.10[-0.23,0.43]$ & - \\
\hline Total (95\% CD) & & & 708 & $707100.0 \%$ & $0.10[-0.05,0.25]$ & 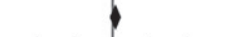 \\
\hline $\begin{array}{l}\text { Heterogeneily. Taur: } \\
\text { Test for overall effect }\end{array}$ & $\begin{array}{l}=0.00 ; C^{2}=0.47,0 \\
z=1.29(P=0.20)\end{array}$ & $f f=3 P$ & $x_{1} \cdot P^{2}=0$ & & & $\begin{array}{ccccc}1 & 1 & & 1 & 1 \\
-2 & -1 & 0 & 1 & 2 \\
\text { Farours Control Fawours Tiotropium }\end{array}$ \\
\hline
\end{tabular}

Figure 6. Mean difference in improvement of quality of life (measured by mini-AQLQ score) between the tiotropium and control groups.

Table 3. Adverse events reported in the studies reviewed.

\begin{tabular}{ccccc}
\hline Adverse Event & $\begin{array}{c}\text { Number } \\
\text { of Studies }\end{array}$ & Tiotropium & Control & P value \\
\hline Asthma Exacerbation & 5 & 216 & 276 & $\mathrm{P}<0.0001$ \\
Nasopharyngitis & 4 & 65 & 76 & $\mathrm{P}=0.37$ \\
Bronchitis & 4 & 21 & 29 & $\mathrm{P}=0.25$ \\
Headache & 4 & 32 & 35 & $\mathrm{P}=0.74$ \\
Upper Respiratory & 4 & 25 & 21 & $\mathrm{P}=0.55$ \\
Tract Infection & & & & \\
\hline
\end{tabular}

\section{Discussion}

This review summarized the current available data from RCTs on the efficacy of tiotropium as an add-on therapy on top of standard controller drugs for patients with uncontrolled asthma. Statistically significant improvements were seen in terms of pulmonary function measures (FEV1 and morning and evening PEF values) as compared with controls. Although no similar existing meta-analyses was available for direct comparison, this result correlated with the observed parallel slowing of FEV1 decline in patients with COPD, another obstructive airways disease, treated with tiotropium. ${ }^{10}$

In terms of clinical outcomes (reduction in frequency of rescue medication use and improvement in quality of life), no statistically significant difference was demonstrated; however, results showed an equivocal trend towards benefit. This was again compatible with the results obtained in a meta-analysis on COPD patients. ${ }^{19}$ Although a statistically significant reduction in exacerbations was observed with tiotropium (replicating its effect in yet another COPD study ${ }^{20}$ ), it was noted that this outcome was not considered among the primary outcomes of any study, being merely reported as an adverse event. Moreover, no studies were able to include other outcomes such as allcause mortality, number of hospitalizations, frequency of ICU admissions, and frequency of mechanical ventilation, among others. In the absence of these hard clinical endpoints, FEV1 may stand as a potential surrogate 
outcome. It has been shown in studies to be predictive of identifying asthmatic patients at increased risk of hospitalization over one year of follow up, in addition to being an excellent predictor of mortality. ${ }^{21}$

The studies included in this review were generally of good quality, with homogeneity consistently observed for all outcome measures across the different trials. A possible limitation, however, is the relative lack of data on the role of tiotropium in uncontrolled asthma, largely due to the novelty of its use in the disease. Publication bias may have also affected the study results to some extent, as statistically significant results are more likely to be published than those affirming a null result. Although the researchers extensively searched for unpublished data, it is with no certainty that all current evidences were retrieved. An attempt to minimize selection bias was done via the presence of pre-specified inclusion and exclusion criteria, performance of a systematic search, and independent evaluation of trial quality by three reviewers.

\section{Conclusion and Recommendations}

Tiotropium, a long-acting anticholinergic, is associated with a statistically significant improvement in pulmonary function in terms of FEV1 and both morning and evening PEF values among patients with uncontrolled asthma. It may also confer possible benefit in reduction of rescue medication use and improvement of quality of life. With these findings, patients with uncontrolled asthma may opt to consider tiotropium as add-on therapy on top of pre-existing doses of standard controller drugs. The authors, however, recommend future endeavors with more clinical outcomes to further strengthen and validate these findings. Such investigations will undoubtedly prove indispensable in improving current guidelines on the management of uncontrolled asthma.

\section{Disclosures and Conflicts of Interest}

No funding was provided by any external source for the study.

\section{References}

1. Global Initiative for Asthma, 2002. Global strategy for asthma management and prevention [Online]. [cited 2012 Sept]. Available from http://www.ginaasthma.org/local/uploads/files/GINAwr02.pdf.

2. British Thoracic Society/Scottish Intercollegiate Guideline Network (SIGN BTS) [British guideline on the management of asthma]. Thorax 2003; 58 Suppl 1:1-94.

3. Kerstjens HA, Engel M, Dahl R, et al. Tiotropium in asthma poorly controlled with standard combination therapy. N Engl J Med. 2012; 367(13):1198-207.

4. Global Initiative for Asthma, 2011. Global strategy for asthma management and prevention [Online]. [cited 2012 Sept]. Available from http://www.ginaasthma.org/local/uploads/files/GINAwr11.pdf.

5. Brown JP, Greville HW, Finucane KE. Asthma and irreversible airflow obstruction. Thorax. 1984; 39(2):131-6.

6. Ulrik CS, Lange P. Decline of lung function in adults with bronchial asthma. Am J Respir Crit Care Med. 1994; 150(3):629-34.

7. Barnes PJ, Woodcock AJ. Difficult asthma. Eur Respir J. 1998; 12(5):1209-18.

8. Bateman ED, Boushey HA, Bousquet J, Busse, et al. Can guidelinedefined asthma control be achieved? The Gaining Optimal Asthma Control Study. Am J Respir Crit Care Med. 2004; 170(8):836-44.

9. van Noord JA, Aumann JL, Janssens E, et al. Comparison of tiotropium once daily, formoterol twice daily, and both combined once daily in patients with COPD. Eur Respir J. 2005; 26(2):214-22.

10. Barr RG, Bourbeau J, Camargo CA, Ram FS. Tiotropium for stable chronic obstructive pulmonary disease: a meta-analysis. Thorax. 2006; 61(10):854-62.

11. Barnes PJ. The pharmacological properties of tiotropium. Chest 2000; 117(2Suppl):63S-6S.

12. Disse B, Speck GA, Rominger KL, Witek TJ Jr, Hammer R. Tiotropium (Spiriva): mechanistical considerations and clinical profile in obstructive lung disease. Life Sci 1999; 64(6-7):457-64.

13. Kapoor AS, Olsen SR, O' Hara C, Puttagunta L, Vethanayagam D. The efficacy of tiotropium as a steroid-sparing agent in severe asthma. Can Respir J. 2009; 16(3):99-101.

14. Park HW, Yang MS, Park CS, et al. Additive role of tiotropium in severe asthmatics and Arg16Gly in ADRB2 as a potential marker to predict response. Allergy. 2009; 64(5):778-83.

15. Westby M, Benson M, Gibson P. Anticholinergic agents for chronic asthma in adults. Cochrane Database Syst Rev 2004; (3):CD003269.

16. Magnussen H, Bugnas B, van Noord J, Schmidt P, Gerken F, Kesten S. Improvements with tiotropium in COPD patients with concomitant asthma. Respir Med. 2008; 102(1):50-6.

17. Bateman ED, Kornmann O, Schmidt P, Pivovarova A, Engel M, Fabbri LM. Tiotropium is noninferior to salmeterol in maintaining improved lung function in B16-Arg/Arg patients with asthma. J Allergy Clin Immunol. 2011; 128(2):315-22.

18. Juniper EF, Guyatt GH, Cox FM, Ferrie PJ, King DR. Development and validation of the Mini Asthma Quality of Life Questionnaire. Eur Respir J 1999; 14(1):32-8.

19. Yohannes AM, Willgoss TG, Vestbo J. Tiotropium for treatment of stable COPD: a meta-analysis of clinically relevant outcomes. Respir Care. 2011; 56(4):477-87.

20. Van den Bruel A. Gailly J. Neyt M. Does tiotropium lower exacerbation and hospitalization frequency in COPD patients: results of a metaanalysis. BMC Pulm Med. 2010; 10:50.

21. Kitch BT, Paltiel AD, Kuntz KM, et al. A Single Measure of FEV1 Is Associated with Risk of Asthma Attacks in Long-term Follow-up. Chest. 2004; 126(6):1875-82. 